\title{
PERANCANGAN DAN IMPLEMENTASI WEBSITE LAYANAN AKADEMIK DI SMA NEGERI 07 BANDAR LAMPUNG
}

\section{DESIGN AND IMPLEMENTATION A WEBSITE FOR ACADEMIC SERVICE AT SMA NEGERI O7 BANDAR LAMPUNG}

\author{
Yohana Tri Utami ${ }^{1}$, Riki Sofyan ${ }^{2}$, Rd. Irwan Adi Pribadi ${ }^{3}$ \\ ${ }^{1}$ Jurusan Ilmu Komputer, Fakultas Matematika dan Ilmu Pengetahuan Alam, Universitas Lampung \\ E-mail: yohana.utami@fmipa.unila.ac.id
}

Dikirim 22 April 2021, Direvisi 12 Juni 2021, Disetujui 29 Juli 2021

\begin{abstract}
Abstrak: Penelitian ini berfokus pada pembuatan website layanan akademik di SMA Negeri 07 Bandar Lampung. Hal tersebut bertujuan untuk merancang dan merealisasikan sistem informasi akademik SMA Negeri 07 Bandar Lampung berbasis web menggunakan Framework Laravel dengan bahasa pemrograman PHP dan MariaDB sebagai database server. Dalam perancangan sistem informasi akademik di SMA Negeri 07 Bandar Lampung yang menggunakan metode Waterfall terbagi menjadi beberapa akses pengguna yaitu tata usaha (admin), guru dan wali kelas dengan masing masing memiliki akses fitur yang berbeda-beda. Dengan adanya website SMA Negeri 07 Bandar Lampung, maka sekolah telah memiliki media alternatif penyedia informasi, sehingga mempermudah dalam pengelolaan dan pencarian data akademik. Pengujian sistem yang telah dilakukan menghasilkan penilaian untuk kepuasan berada pada penilaian rata rata 99,75 \% dengan kategori "Sangat Baik".
\end{abstract}

Kata kunci: Website, Framework Laravel, Akademik, Waterfall.

Abstract: This research focuses on creating a website for academic services at SMA Negeri 07 Bandar Lampung. It aims to design and realize a web-based academic information system for SMA Negeri 07 Bandar Lampung using the Laravel Framework with the PHP programming language and MariaDB as the database server. In designing an academic information system at SMA Negeri 07 Bandar Lampung that uses the Waterfall method, it is divided into several user accesses, namely administration (admin), teachers and homeroom teachers, each of which has access to different features. With the existence of the SMA Negeri 07 Bandar Lampung website, the school has an alternative media for providing information, making it easier to manage and search for academic data. System testing that has been carried out results in an assessment for satisfaction at an average rating of $99.75 \%$ with the "Very Good" category.

Keywords: Website, framework Laravel, academic, Waterfall.

\section{PENDAHULUAN}

Teknologi Informasi dan komunikasi sangat berperan dalam mendukung dan meningkatkan efisiensi dalam mengelola kegiatan sehari-hari, serta memungkinkan pekerjaan dilakukan dari mana saja

Kemajuan teknologi saat ini berkaitan erat dengan kemajuan internet yang dapat menghubungkan setiap pengguna dari satu komputer ke komputer yang lainnya yang ada di dunia ini. Indonesia adalah salah satu negara di Asia Tenggara dengan pertumbuhan internet paling cepat di dunia bersamaan dengan Singapura, Thailand, Vietnam, Filiphina, dan Malaysia.
Kemajuan teknologi saat ini semakin pesat dimana hampir seluruh instansi sudah menggunakan berbagai macam teknologi informasi untuk mempermudah pekerjaan seseorang dan meminimalisir kesalahan.

Seperti halnya kegiatan akademik di SMA Negeri 07 Bandar Lampung, yang masih belum terintegrasi kedalam database server dimana staff akademik masih menggunakan aplikasi berbasis offline yang terbuat dari software excell. Hal ini mempersulit kinerja antar staff akademik untuk saling berbagi dan akses sistem sekolah karena masih bersifat offline. 
Berdasarkan dari masalah tersebut, maka akan dibuatlah suatu sistem informasi data akademik sekolah berbasis web yang dapat mengelola kegiatan akademik di SMA Negeri 07 Bandar Lampung yang dapat terintegrasi kedalam server.

Dengan adanya sistem informasi yang akan dibuat tersebut, diharapkan akan mempermudah kinerja staff akademik untuk berintegrasi satu dengan yang lain melalui sistem informasi yang ada sehingga dapat memaksimalkan kinerja staff akademik dan menambah efisiensi waktu saat bekerja.

\section{LANDASAN TEORI}

\section{A. Sistem}

Sistem adalah sekelompok elemenelemen yang terintegrasi dengan tujuan yang sama untuk mencapai tujuan (McLeod, 2004) dalam (Firman dkk., 2016). Sedangkan definisi serupa juga disampaikan oleh Kristanto, yang menyatakan bahwa Sistem adalah jaringan kerja dari prosedur - prosedur yang saling berhubungan, berkumpul bersama - sama untuk melakukan suatu kegiatan atau menyelesaikan suatu sasaran tertentu (Kristanto, 2013).

B. Informasi

Informasi adalah data yang diolah menjadi bentuk yang lebih berguna dan lebih berarti bagi yang menerima (Jogiyanto, 2005). Sedeangkan menurut Oetomo Informasi adalah hasil pemrosesan data yang diperoleh dari setiap elemen sistem tersebut menjadi bentuk yang mudah dipahami dan merupakan pengetahuan yang relevan yang dibutuhkan oleh seseorang untuk menambah pemahamannya terhadap fakta - fakta yang ada (Oetomo, 2002)

\section{Sistem Informasi}

Sistem informasi adalah suatu sistem di dalam suatu organisasi yang mempertemukan kebutuhan pengolahan transaksi harian, mendukung operasi, bersifat manajerial dan kegiatan strategi dari suatu organisasi dan menyediakan pihak luar tertentu dengan laporan-laporan
(Jogiyanto, 2005). Sistem informasi juga sangat diperlukan dalam pengambilan keputusan yang logis sehingga membutuhkan pemahaman tentang masalah dan pengetahuan mengenai alternatif pemecahannya. Informasi yang lebih tepat menghasilkan keputusan yang lebih baik. Kualitas suatu informasi tergantung dari 3 (tiga) hal 11 yaitu, informasi harus akurat (accurate), tepat waktu (timelines), dan relevan (relevance) (Lipursari, 2015).

D. Sistem Informasi Akademik

Sistem informasi akademik adalah sebuah sistem yang digunakan untuk melakukan pendataan serta proses pengolahan data yang baik, rapi, dan terorganisir dalam suatu lembaga pendidikan. Sistem informasi akademik menggunakan metode pendataan dan pengolahan data kesiswaan secara komputerisasi bertujuan untuk dapat di proses dengan administrasi yang baik pada waktu pendaftaran, pembagian kelas, pembagian wali kelas, dan guru (Pradipta, 2020).

\section{E. PHP Hypertext Processor (PHP)}

PHP atau kependekan dari Hypertext Preprocessor adalah salah satu bahasa pemrograman open source yang sangat cocok atau dikhususkan untuk pengembangan web dan dapat ditanamkan pada sebuah skrip HTML. Bahasa PHP dapat dikatakan menggambarkan beberapa bahasa pemrograman seperti C, Java, dan Perl serta mudah untuk dipelajari. PHP merupakan bahasa scripting server - side, dimana pemrosesan datanya dilakukan pada sisi server. Sederhananya, server lah yang akan menerjemahkan skrip program, baru kemudian hasilnya akan dikirim kepada client yang melakukan permintaan (Firman dkk., 2016)

\section{F. Framework Laravel}

Framework laravel adalah sebuah kerangka kerja open source yang diciptakan oleh Taylor Otwell. Laravel merupakan framework bundle, migrasi dan artisan CLI 
(Command Line Interface) yang menawarkan seperangkat alat dan arsitektur aplikasi yang menggabungkan banyak fitur terbaik dari kerangka kerja seperti Codeigniter, Yii, ASP.NET MVC, Ruby on Rails, Sinatra dan lain-lain. Laravel memiliki seperangkat sangat kaya fitur yang akan meningkatkan kecepatan pengembangan web (Handika dan Purbasari, 2018)

\section{G. Model-View-Controller (MVC)}

Pola MVC memecahkan sebuah aplikasi menjadi tiga modul asosiasi: model, view, dan controller. Model adalah logika bisnis dari aplikasi dan inti dari sebuah aplikasi. View adalah user interface dari controller. Yang merupakan muka umum untuk respon event pengguna. Komponen controller mengimplementasi flow yang mengontrol antara view dan model (Chanchai, 2020). Definisi teknis dari arsitektur MVC dibagi menjadi tiga lapisan (Hidayat dan Surarso, 2012).

\section{H. Teknologi Informasi}

Teknologi informasi merupakan suatu piranti yang dapat membantu pekerjaan manusia di era digital. teknologi informasi berperan sebagai alat bantu untuk memudahkan pengelolaan suatu sumber daya yang dimiliki oleh suatu organisasi(Djaelangkara, 2015).

\section{Maria DB}

Maria DB merupakan salah satu database server yang digunakan untuk menyimpan dan memanajemen data. MariaDB tidak jauh berbeda dengan MySQL, karena MariaDB merupakan versi pengembangan terbuka dan mandiri 15 dari MySQL (Warman dan Ramdaniansyah, 2018).

\section{J. Unified Modelling Language (UML)}

Unified Modeling Language (UML) adalah sebuah bahasa yang berdasarkan grafik atau gambar untuk memvisualisasi, menspesifikasikan, membangun, dan dokumentasi dari sebuah sistem pengembangan software berbasis OOP
(Object-Oriented Programming) (Suendri, 2018). UML adalah salah satu standar bahasa yang banyak digunakan di dunia industri untuk mendefinisikan kebutuhan sistem, membuat analisis dan desain, serta menggambarkan arsitektur dalam pemrograman berorientasi objek (Wira dkk., 2019).

\section{METODOLOGI}

\section{A. Jenis Penelitian}

Metode yang penulis gunakan dalam melakukan pengembangan sistem ini yaitu menggunakan metode waterfall. Dalam tahapan metode waterfall terdapat beberapa tahapan bagian dalam pengembangan sistem yang dapat penulis uraikan sebagai berikut :

a) Analisis

Pada tahapan analisis, penulis membuat suatu analisis permasalahan yang ada dan menentukan kebutuhan sistem yang akan dibangun.

b) Perancangan

Penulis membuat gambaran umum sistem yang akan dibangun

c) Implementasi

Melakukan pembangunan sistem dengan coding

d) Pengujian

Pengujian dilakukan untuk dapat memastikan sistem sesuai dengan kebutuhan

e) Pemeliharaan

Pemeliharaan dimungkinkan untuk perubahan yang diperlukan agar sistem dibangun dengan baik 


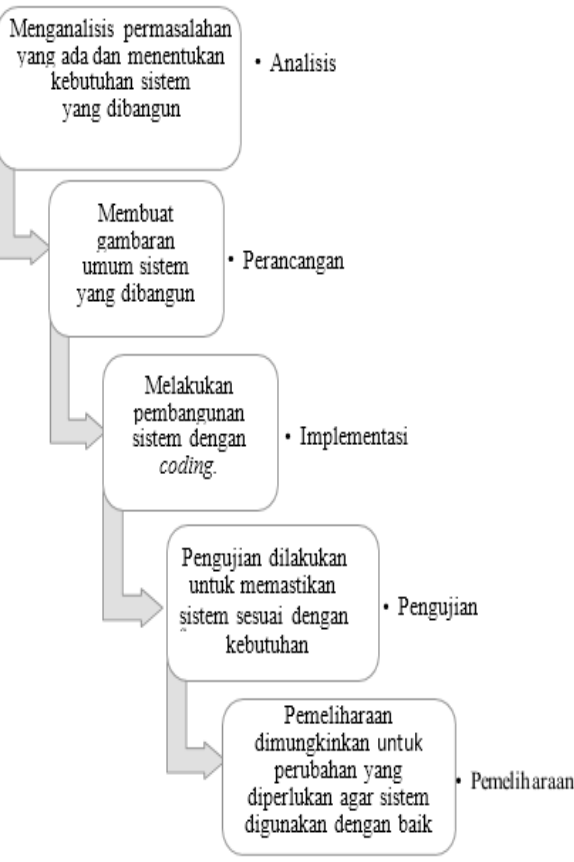

Gambar 1. Alur Penelitian

B. Lokasi Penelitian

Penelitia ini dilakukan selama 2 bulan yaitu Oktober - November 2020 (mengikuti waktu yang disediakan) di SMA Negeri 07 Bandar Lampung dan Gedung Ilmu Komputer Universitas Lampung.

\section{Teknik Pengumpulan Data}

a) Data Primer

Data primer didapatkan dari hasil wawancara dengan pihak pegawai SMA Negeri 7 Bandar Lampung tentang kegiatan pengelolaan data akademik yang sedang berlangsung.

\section{b) Data Sekunder}

Data sekunder didapat dari buku, jurnal, dan internet yang menyajikan informasi mengenai sistem pengelolaan data akademik berbasis web.

\section{Analisis Sistem}

a) Analisis Masalah

Setelah melakukan wawancara dengan staf tata usaha dan tim IT di SMA Negeri 07 Bandar Lampung, diketahui bahwa dalam pengelolaan data akademik dan perekapan data siswa sering terjadi kesalahan dan memiliki beberapa masalah yang harus diselesaikan. Masalah tersebut diantaranya pencarian biodata siswa, mencetak nilai raport, pencarian data pegawai sekolah (meliputi guru dan staf tata usaha), sistem penerimaan siswa baru yang masih manual atau siswa datang langsung ke sekolah. Akibatnya, pencarian data siswa membutuhkan waktu yang lama karena penyimpanan yang tidak terstruktur dan tidak sesuai dengan kategorinya. Kemudian ditambah lagi masalah berupa penerimaan siswa baru yang masih bersifat offline dimana siswa harus datang langsung ke sekolah dan dicatat ulang secara manual oleh tata usaha terkait biodata akademik siswa yang tentu saja membutuhkan waktu yang lama mengingat banyaknya siswa yang mendaftar setiap tahun ajaran baru.

b) Analisis Kebutuhan Sistem

Pada tahap analisis kebutuhan sistem, penulis telah merancang pengelolaan data akademik di SMA Negeri 07 Bandar Lampung, maka di buatlah suatu sistem akademik yang diharapkan dapat memanajemen data siswa berdasarkan kebutuhan. Penulis telah mendeskripsikan kebutuhan sistem ke dalam modul-modul use case diagram.

\section{HASIL DAN PEMBAHASAN}

Sistem informasi manajemen data akademik berbasis web di SMA Negeri 07 Bandar Lampung adalah sistem yang dibuat untuk mempermudah dalam mengelola data akademik sekolah yang efektif dan efisien. Kegiatan akademik tersebut meliputi mengolah data siswa baru, mata pelajaran, siswa, guru, tata usaha, data mutasi siswa, kelas, berita, nilai siswa, rekap data siswa, rekap data guru, rekap data tata usaha, mengelola aktivitas siswa meliputi (sikap, ekstrakurikuler, prestasi, ketidakhadiran, catatan wali kelas) dan mencetak rapor siswa.

Sistem manajemen data akademik berbasis web di SMA Negeri 07 Bandar Lampung terdiri dari halaman depan (front end) dan halaman belakang (back end) 
sistem. Pada bagian halaman depan sistem terdapat beberapa fitur diantaranya data siswa aktif, guru, kontak, info sekolah, berita. Terdapat dua tombol button yaitu login (masuk sistem) dan daftar siswa baru. Halaman login digunakan pengguna untuk masuk kedalam sistem dan halaman daftar digunakan siswa untuk mendaftar sebagai siswa baru. Pada bagian halaman berita, pengguna dapat melihat berita yang di post oleh admin dan dapat melihat detail dari berita. Sistem informasi yang telah diimplementasikan ke dalam bentuk coding memiliki 5 hak akses yaitu super admin, admin (tata usaha),wali kelas, guru dan siswa.

\section{A. Implementasi}

Tahap implementasi dilakukan setelah tahap analisis dan perancangan sistem selesai. Hasil dari implementasi sistem pada Sistem Manajemen Data Akademik Berbasis Web di SMA Negeri 07 Bandar Lampung ditunjukkan dengan tampilan sebagai berikut.

1) Halaman Awal Masuk Sistem

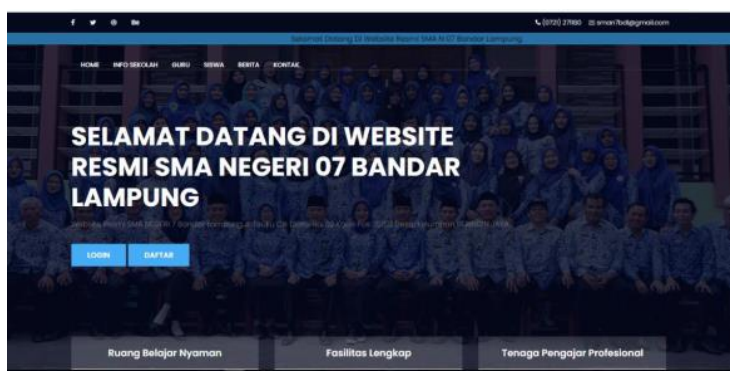

Gambar 2. Halaman awal masuk sistem

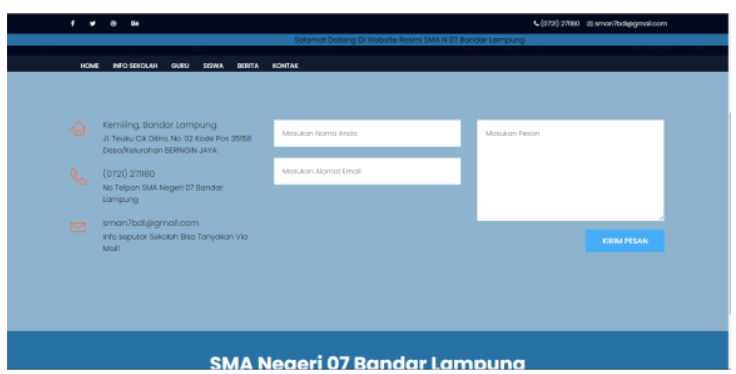

Gambar 3. Tampilan halaman kontak

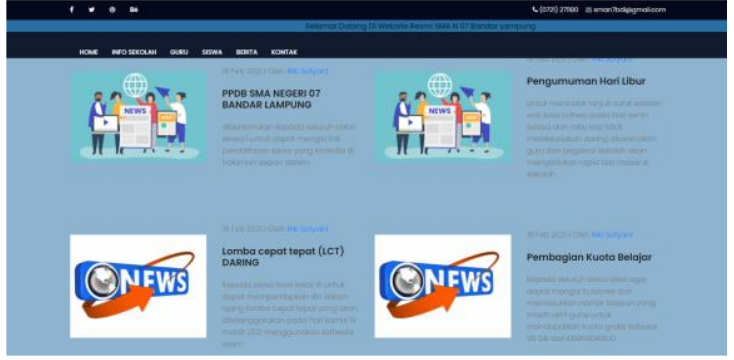

Gambar 4. Tampilan Halaman Berita

2) Menampilkan Halaman Daftar Siswa Baru

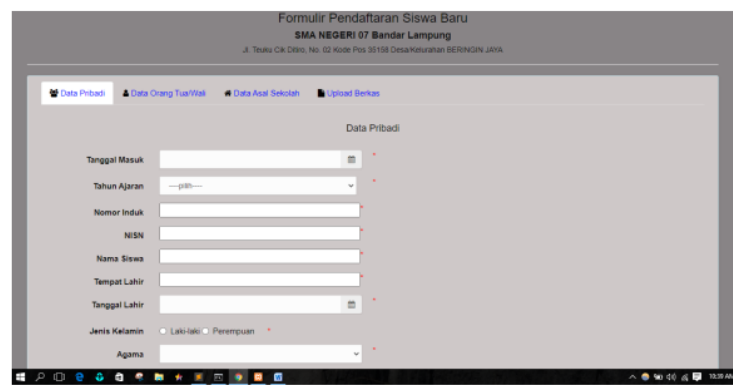

Gambar 5. Tampilan Halaman Daftar Siswa Baru

3) Menampilkan Halaman status pendaftaran

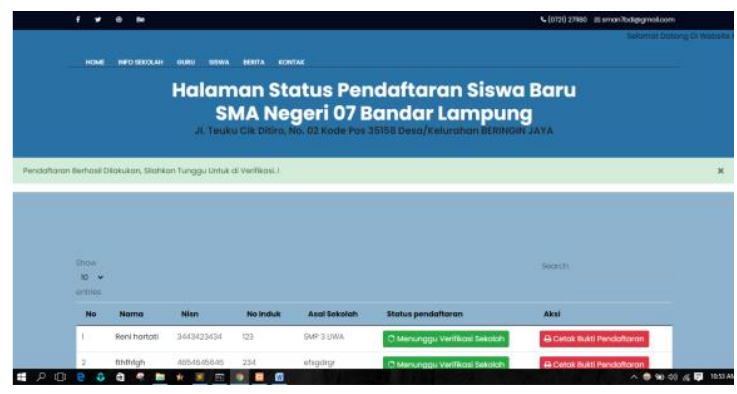

Gambar 6. Tampilan Halaman Status Pendaftaran Siswa Baru

4) Menampilkan halaman login

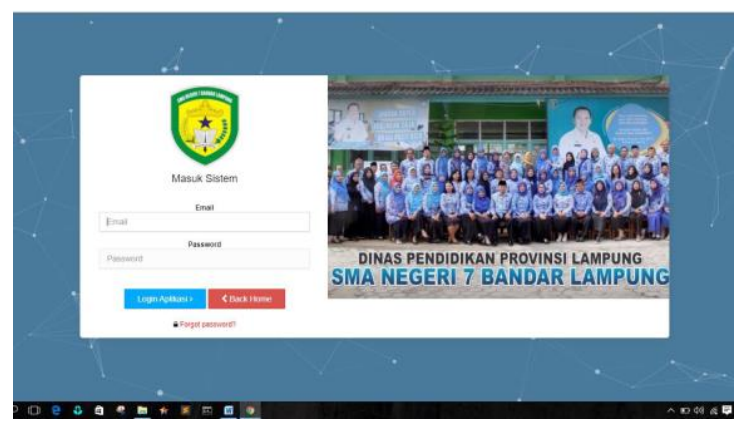

Gambar 7. Tampilan Halaman Login 
5) Tampilan halaman dashboard siswa

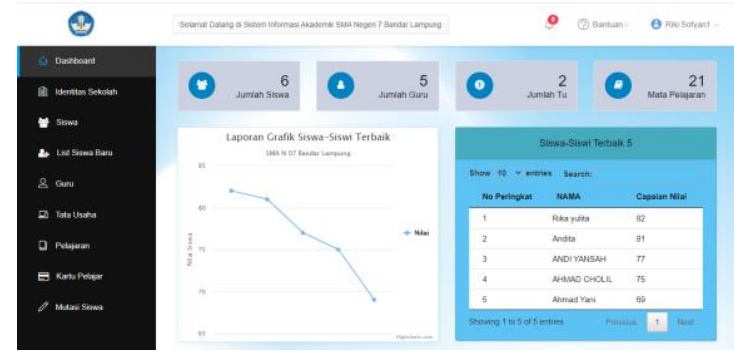

Gambar 8. Halaman dashboard siswa

6) Tampilan Halaman Identitas Sekolah

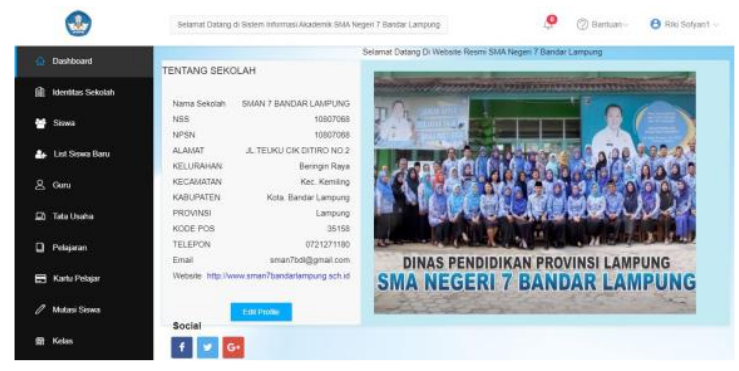

Gambar 9. Halaman Identitas Sekolah

7) Tampilan Halaman Siswa

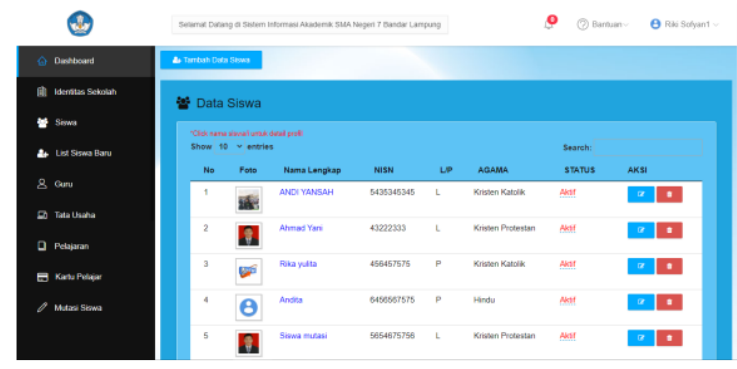

Gambar 10. Tampilan Halaman Siswa

8) Tampilan Halaman Profil Siswa

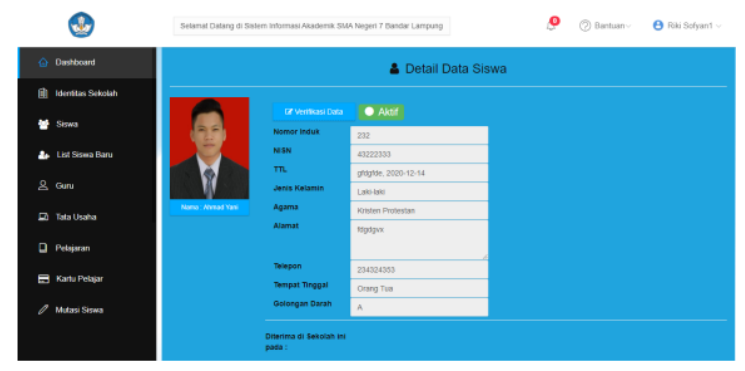

Gambar 11. Halaman Profil Siswa
9) Tampilan Halaman Data Siswa Baru

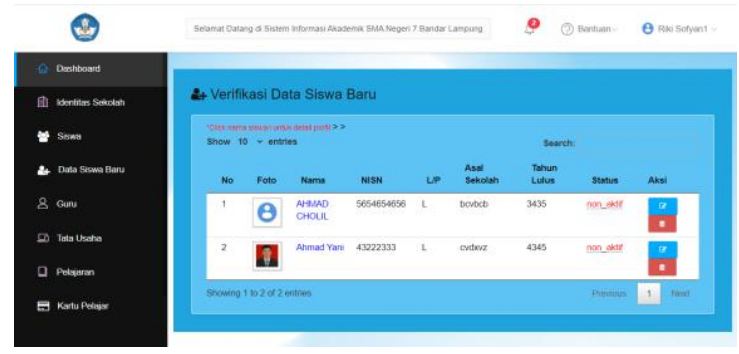

Gambar 12. Halaman Siswa Baru

10) Tampilan Halaman Guru

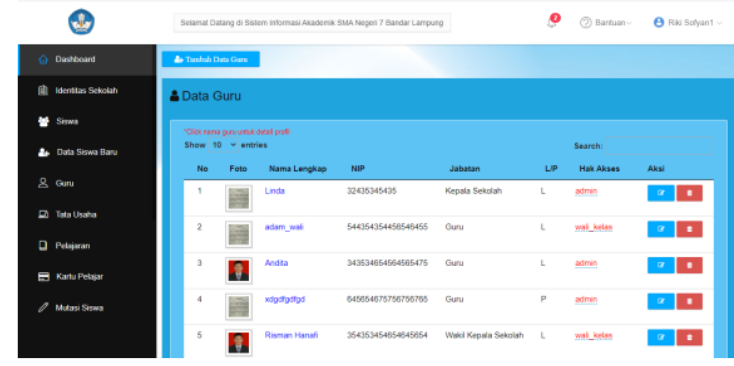

Gambar 13. Tampilan Halaman Guru

11) Tampilan Halaman Tata Usaha

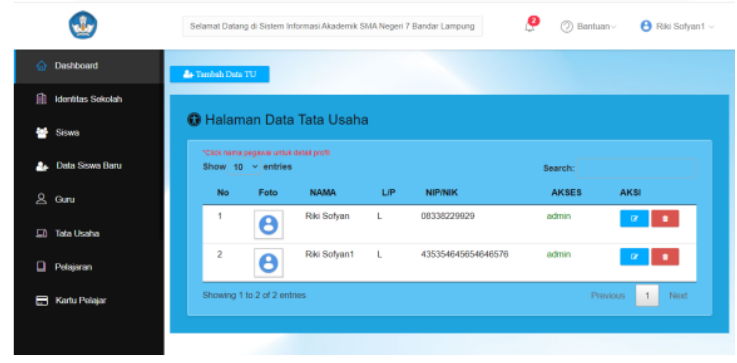

Gambar 14. Halaman Tata Usaha

12) Tampilan Halaman Mata Pelajaran

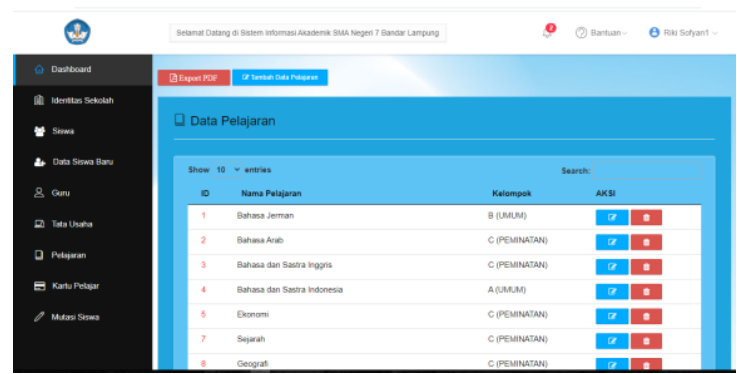

Gambar 15. Halaman Mata Pelajaran 
13) Tampilan Halaman Cetak Kartu Pelajar

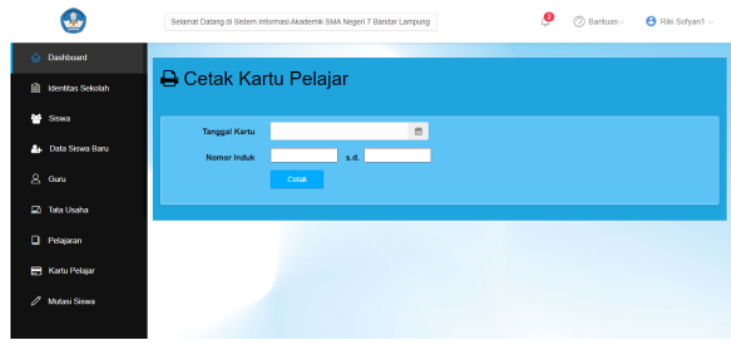

Gambar 16. Halaman Cetak Kartu Pelajar

14) Tampilan Halaman Mutasi Siswa

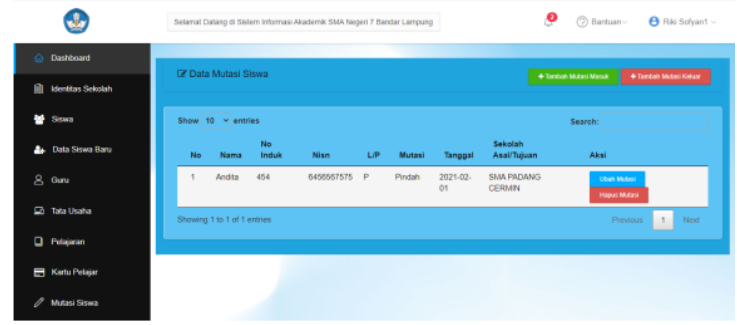

Gambar 17. Halaman Mutasi Siswa

15) Tampilan Halaman Kelas

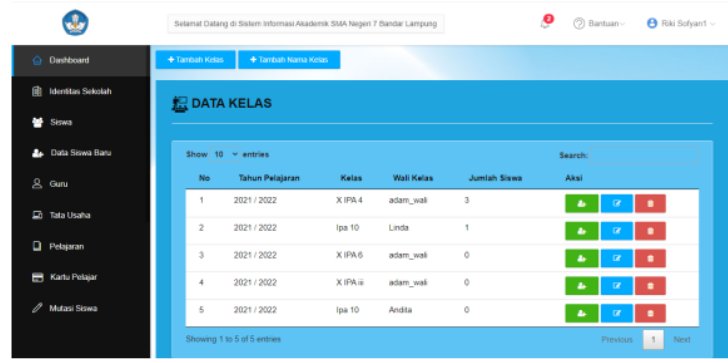

Gambar 18. Tampilan Halaman Kelas

16) Tampilan Halaman Post Berita

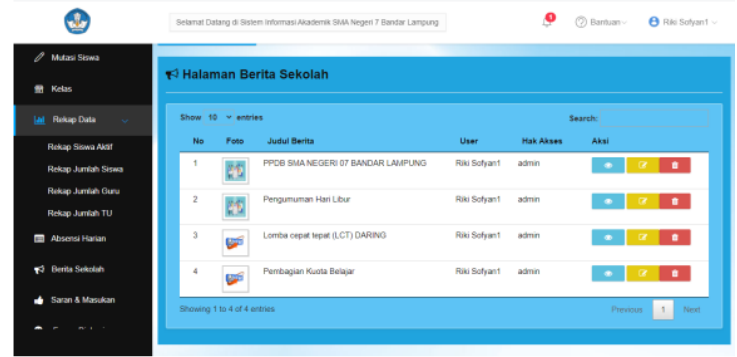

Gambar 19. Tampilan Halaman Post
17) Tampilan Halaman Saran dan masukan

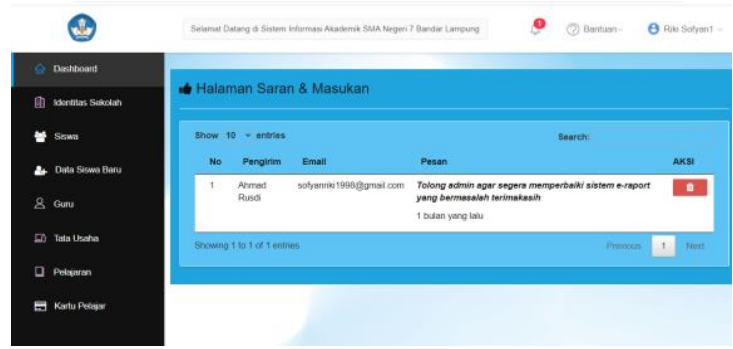

Gambar 20. Tampilan Halaman Saran

18) Tampilan Halaman Forum Diskusi
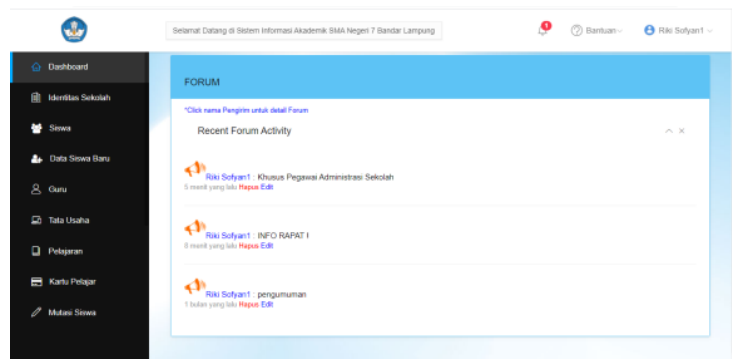

Gambar 21. Tampilan Halaman Forum Diskusi

19) Tampilan Halaman Siswa Asuh (Wali Kelas)

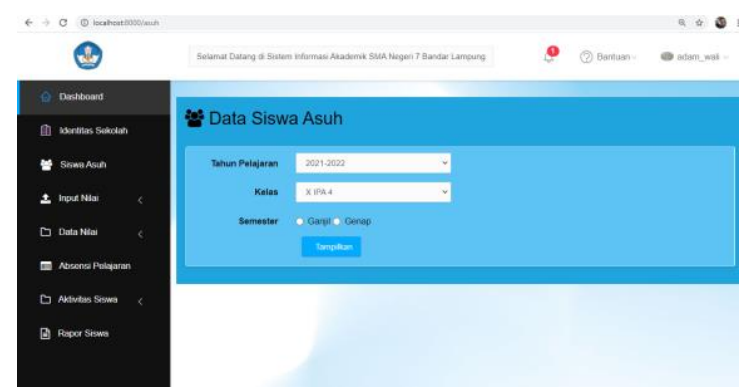

Gambar 22. Halaman Siswa Asuh

20) Tampilan Halaman Input Nilai Pengetahuan dan Keterampilan

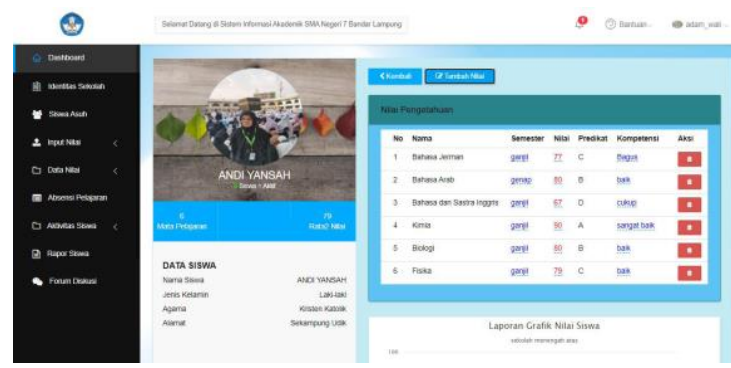

Gambar 23. Halaman Input Nilai Pengetahuan dan Keterampilan 
21) Tampilan Halaman Data Nilai Pengetahuan dan Keterampilan
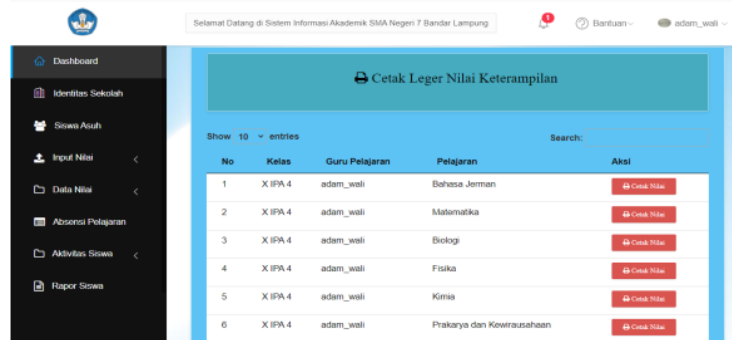

Gambar 24. Halaman Data Nilai

Pengetahuan dan Keterampilan

22) Tampilan Halaman Absensi Pelajaran

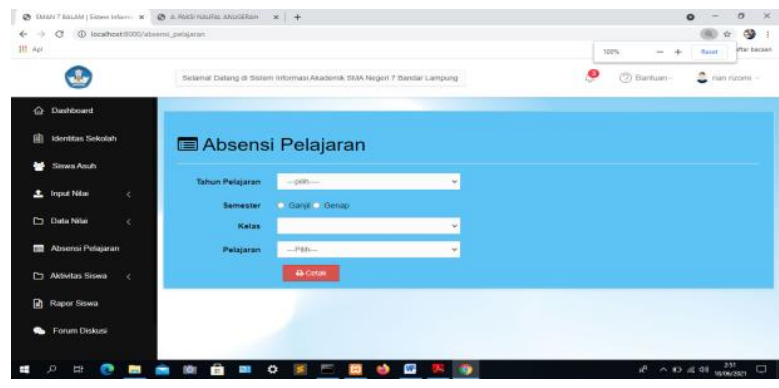

Gambar 25. Tampilan Halaman Input Absensi Pelajaran

23) Tampilan Halaman Cetak Absensi Pelajaran

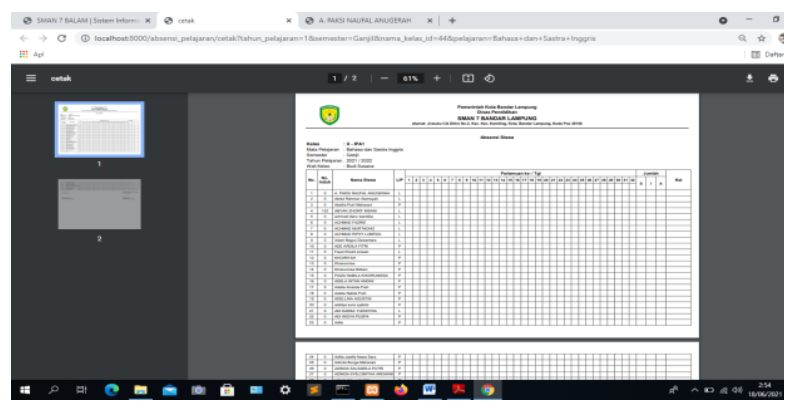

Gambar 26. Tampilan Halaman Cetak Absensi Pelajaran.

24) Tampilan Halaman Data Cetak Rapor Siswa

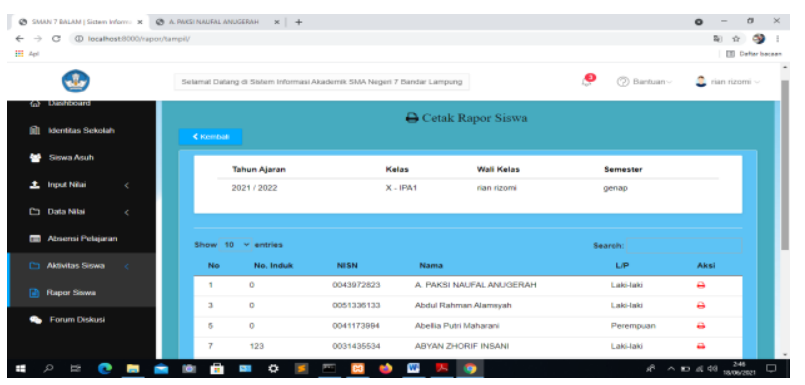

Gambar 27. Halaman Data Cetak Rapor Siswa
25) Tampilan Halaman Cetak Rapor Siswa

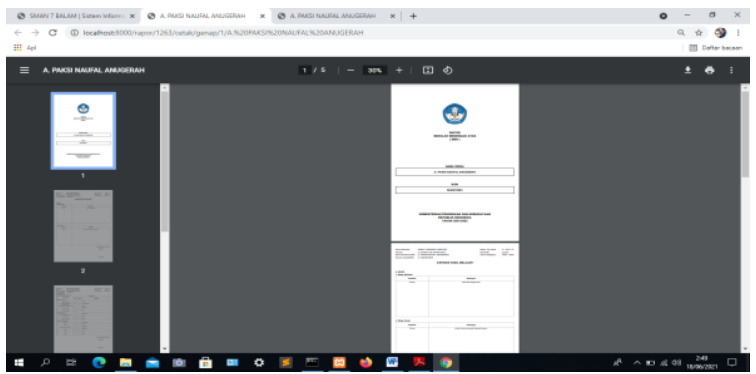

Gambar 28. Halaman Cetak Rapor Siswa

\section{B. Hasil Pengujian}

Sistem informasi ini dikembangkan menggunakan suatu teknik pengujian black box testing dengan metode Equivalence Partitioning (EP). EP bekerja dengan cara membagi domain masukan dari program ke dalam kelas uji sehingga test case dapat diperoleh.

Pengujian dilkukan dengan dua kategori yaitu pengujian fungsional dan non fungsional. Pengujian fungsional dilakukan user dengan cara mencoba satu demi satu fitur yang tersedia di sistem apakah fitur berjalan dengan baik dan ssesuai dengan kebutuhan user. Pengujian non fungsional dilakukan ketika user telah mencoba menjalankan sistem dan memberikan penilaian atas hasil dari eksplorasi dan mengisi kuisioner yang disediakan oleh penulis. Hasil dari kuisioner akan dihitung menggunakan skala likert dengan range antara 1 sampai 5 (sangat kurang - sangat baik). Pertanyaan yang diberikan pada kuisioner sebanyak 16 pertanyaan. Hasil jawaban kuisioner dapat dilihat pada Tabel 1. 
Tabel 1. tabel hasil kuisioner.

\begin{tabular}{ccccccccc}
\hline \multicolumn{7}{c}{ Pengujian Non Fungsional Sistem Informasi Manajemen Data Akademik SMA Negeri 07 Bandar } \\
Lampung
\end{tabular}

C. Analisis Hasil Pengujian

Pengujian yang telah dilakukan di SMA Negeri 07 Bandar Lampung merupakan pengujian fungsional sistem. Secara keseluruhan, hasil telah sesuai dengan apa yang diharapkan oleh sekolah. Hasil pengujian menunjukkan bahwa fungsi fungsi pada Sistem Informasi Manajemen Data Akademik SMA Negeri 07 Bandar Lampung telah berjalan dengan baik. Pada saat melakukan pengujian sistem yang telah penulis buat, penilaian untuk kepuasan berada pada penilaian rata rata $99,75 \%$ dari 10 responden yang terdiri dari guru, walikelas dan tata usaha (admin) dengan kategori "Sangat Baik" menurut perhitungan sekala likert. Pada pengujian yang dilakukan terdapat beberapa masukan untuk meningkatkan efektivitas pengguna sistem dengan menambah beberapa fitur tambahan.

\section{KESIMPULAN}

Berdasarkan dari hasil penelitian yang penulis lakukan dapat disimpulkan telah dibangun Sistem Informasi Data Akademik Berbasis Web di SMA Negeri 07 Bandar
Lampung Menggunakan Framework Laravel untuk membantu pegawai sekolah dalam mengelola proses akademik di SMA Negeri 07 Bandar Lampung. Pengujian sistem yang telah dilakukan menghasilkan penilaian untuk kepuasan berada pada penilaian rata rata 99,75\% dengan kategori "Sangat Baik".

\section{SARAN}

Berikut beberapa saran yang telah didapat antara lain sebagai berikut:

1. Sistem memiliki fitur lupa kata sandi dan sistem terhubung dengan email pada pengguna dengan akses sebagai pegawai sekolah.

2. Mengembangkan Sistem Manajemen Data Akademik Berbasis Web di SMA Negeri 07 Bandar Lampung ke dalam bentuk aplikasi android

3. Pengembangan fitur chat pada Forum Diskusi secara realtime

4. Sistem memiliki fitur monitoring kinerja guru dan pegawai sekolah yang dikelola oleh Kepala Sekolah dan Dinas Pendidikan Kota Bandar Lampung

5. Fitur scan barcode pada absensi pelajaran dan harian siswa

6. Pengisian absensi siswa dilakukan secara otomatis oleh masing-masing siswa/i.

\section{DAFTAR PUSTAKA}

Anam, K. (2018). Analisa Dan Perancangan Sistem Informasi Akademik Berbasis Web Pada Mi Al-Mursyidiyyah Al'Asyirotussyafi'Iyyah. 11(2), 207-217. Jurnal Teknik Informatika.

Djaelangkara, dkk (2015). Perancangan Sistem Informasi Akademik Sekolah Berbasis Web Studi Kasus Sekolah Menengah Atas Kristen 1 Tomohon, 23018402. e-jurnal Teknik Elektro dan Komputer

Firman, A., Wowor, H. F., Najoan, X., Teknik, J., Fakultas, E., \& Unsrat, T. (2016). Sistem Informasi Perpustakaan 
Online Berbasis Web. 5(2), 29-36. Jurnal Teknik Elektro Dan Komputer

Handika, I. G., \& Purbasari, A. (2018). Pemanfaatan Framework Laravel Dalam Pembangunan Aplikasi E-Travel Berbasis Website. 1329-1334. Konferensi Nasional Sistem Informasi STMIK Atma Luhur Pangkalpinang

Hidayat, A., \& Surarso, B. (2012). Penerapan Arsitektur Model View Controller (MVC) Dalam Rancang Bangun Sistem Kuis Online Adaptif. 57-64. Seminar Nasional Teknologi Informasi Dan Komunikasi.

Jamaliah., Skripsi: (2011). Sistem informasi akademik berbasis client server. Jakarta. UIN Syarif Hidayatullah.

Jogiyanto H.M. 2005. Analisis dan Desain Sistem Informasi. Andi : Yogyakarta

Lipursari, A. (2013). Konsep Dasar Informasi. Peran Sistem Informasi Manajemen (Sim), 3(2), 1-9. Semarang : Jurnal STIE Semarang.

Oetomo, Budi Sutedjo Dharma. (2002). Perencanaan dan Pembangunan Sistem Informasi. Yogyakarta: Andi.

Pradipta,A,A.,Skripsi: (2020). perancangan dan implementasi sistem manajemen dalam pengelolaan data akademik berbasis web di SMA Negeri 01 Liwa. Lampung: Universitas Lampung

Suendri. (2018). Implementasi Diagram UML (Unified Modelling Language) Pada Perancangan Sistem Informasi Remunerasi Dosen Dengan Database Oracle (Studi Kasus: UIN Sumatera Utara Medan). 3(1), 1-9. Jurnal Ilmu Komputer Dan Informatika.

Warman, I., dan Ramdaniansyah, R. (2018). Analisis perbandingan kinerja query database management system (DBMS) antara MySQL 5.7.16 dan MariaDB 10.1. 6(1), 32-41. Padang : Institut Teknologi Padang.

Saifuddin (2017). "Gratis Schooling" Evaluation At The Senior High Schools/Vocational Schools In Bandar Lampung City”. Jurnal Inovasi Pembangunan Volume. 05 No. 02. 